\title{
COULD YOU REPEAT THAT? A PRELIMINARY STUDY OF THE EFFECTIVENESS OF COURSE MANAGEMENT SYSTEMS IN THE BLENDED ENVIRONMENT
}

\author{
Matt Campbell, University of South Alabama, MattCampbell@usouthal.edu
}

\begin{abstract}
The use of technology in education is growing at a rapid pace. Those in academia are looking for innovative and effective ways to reach students who have less time and more choices than ever before. Many institutions are using course management systems to provide instruction for online courses as well as blended courses. Previous studies that have examined the difference in student performance between traditional, online, and blended course models don't address two important issues: actual system usage and the use of novel versus non-novel content. In this preliminary study we attempt to assess the value provided to students through the use of blended course instruction. Our findings suggest that not all online instructional content is beneficial to students. While the use of a content management system to share content not covered in traditional meetings (novel content) was beneficial, we found no significant impact for the use of instructional content that had already been presented in the face-to-face meetings (non-novel content). Unfortunately, student usage of the system tended to focus more on non-novel content.
\end{abstract}

Keywords: course management systems, online learning, Moodle, education technology

\section{INTRODUCTION}

The use of online technologies to aid in education has been around for some time. Course management systems (CMS), also commonly referred to as Learning Management System (LMS), Learning Support System (LSS), and Learning Platforms (LP), are software packages that allow instructors to share online content with students as well as conduct other functions of teaching [3]. These systems can be used wholly online or to supplement traditional face-to-face courses. Examples of widely implemented course management systems are Blackboard, WebCT, and Moodle.

CMS allow students to accomplish many of the functions of a traditional classroom course in an online format including: checking course grades; viewing lecture slides, assignment instructions, and the course syllabus; reading course announcements; chatting with classmates; making presentations; and accessing supplemental course material. In addition, CMS can record a great deal of data about students' activities which can aid the instructor in evaluating course participation as well as provide an opportunity to study the way students use the system [1]. Although different software packages provide different levels of granularity in their reporting, most provide at least basic reporting capabilities on student interaction with the system. The widespread use of these systems necessitates the question of how they impact student performance and, ultimately, student learning.

Our area of interest is whether a CMS provides benefits to students when used in conjunction with traditional faceto-face instruction. To answer this question, we looked at the use of the Moodle Course Management System in place at a major university in the Southeastern US.

A 2009 meta analysis commissioned by the U.S. Department of Education [6] looked at studies that examined online learning and found that, overall, courses that combined elements of traditional face-to-face instruction with elements of online learning resulted in better student performance than either purely online or purely traditional classes. This type of instruction is referred to as blended. In many studies considered, separate classes were compared with one being a traditional face-to-face class (control) and the other implementing some elements of online learning (blended).

Our study takes a different approach by attempting to relate student usage of a CMS to student performance in a single instance of a class. We believe this provides a better method of controlling differences between courses than studies that use students from two separate classes that may have not even been conducted during the same semester. 
Volume XII, No. 2, pp 95-99, 2011

\section{LITERATURE REVIEW}

Many universities are quick to tout the benefits of online degree programs, especially for non-traditional students (e.g. attend class from anywhere at any time); however, some may question the effectiveness of these programs. Previous research, though, has not substantiated these doubts. In fact, many studies that have compared online and traditional learning environments have found no significant differences in students' performance between the two alternatives [2, 4, 5]. Piccoli et al. [2] did note, however, that student satisfaction was lower for online students than for those in traditional courses. This could be due to student expectations of personal contact with the instructor.

In an attempt to achieve some of the benefits of online instruction while still allowing for face-to-face interaction, some schools have implemented a blended model that combines face-to-face instruction with support from an online CMS. They do this with the assumption that students will still receive the benefit of face-to-face interaction along with the benefit of being able to access course material at any time through the course management system. This prompts the question: does CMS use improve student performance when used with a traditional face-to-face course?

The U.S. DOE meta analysis looked at studies that examined online learning and found that, overall, courses that combined elements of traditional face-to-face instruction combined with elements of online learning (blended model) resulted in better student performance than either purely online or purely traditional face-to-face classes. In many studies considered, separate classes were compared with one being a traditional face-to-face class (control) and the other implementing some elements of online learning.

However, we believe that comparing two separate classes is not the best way to investigate the impact of a blended course model on student performance. One important factor that was missing in studies considered in the meta analysis was system usage. When a blended class is compared to a separate traditional class, we are forced to make an assumption about whether students in the blended class actually used the system and to what degree they used it. It is also arguable that it is impossible to truly control for all of the many variables that can make a section of a course taught in one semester different from the same course taught in a subsequent semester, even if the same instructor and book are used in both.

Based on the findings of the Department of Education meta analysis - that students in blended courses do better than students in traditional face-to-face courses - we want to examine the hypothesis that increased student usage of online elements in a blended course leads to better performance. Therefore, we propose that:

H1. A higher level of usage of a CMS will result in a higher course grade.

Another issue that was not examined in previous studies was the impact of overlap between online and face-to-face content. If the online content is an exact copy of what is presented in the face-to-face meetings, does it provide any benefit? We believe that accessing information not fully discussed in the face-to-face meetings (novel content) through the CMS is more beneficial for students than accessing information that mirrors what was presented in the face-to-face meetings (non-novel). For example, accessing project information that was only summarized in class may be more beneficial for a student than accessing PowerPoint slides that were fully discussed in class. Therefore, we propose that:

H2. A student's usage of the CMS to access novel content will have a greater positive impact on their course performance than a student's use of the CMS to access non-novel content.

We also believe that students are more likely to access novel content through the CMS than non-novel content since they ostensibly have already had access to the non-novel content during the face-to-face meetings.

H3. A student will use a CMS to access novel content more often than using it to access non-novel content. 
Volume XII, No. 2, pp 95-99, 2011

\section{METHODOLOGY}

Moodle, an open source CMS, was used to supplement face-to-face instruction in an introductory management information systems (MIS) course at a large university in the Southeastern United States. A study was undertaken to determine if the student's use of the CMS had an impact upon that student's grade in the course.

Seventy-six students out of a total class enrollment of seventy-seven (98.7\%) were given extra credit in the course for agreeing to participate. Students were advised that their use of the online course management software would be logged, but that amount of usage would not be used in the calculation of their course grade.

At the beginning of the semester, students were advised by the instructor of the functions available to them through the use of the Moodle system. These functions included viewing the course lecture slides and course project information.

Because the course had traditional face-to-face meetings, the lecture slides available for students through the CMS were a duplication of information that was presented during the face-to-face class. However, while basic information on the course project was presented to the students during the face-to-face meetings, additional novel information was available only through the CMS. Students were informed of this during the face-to-face meetings.

There are numerous approaches that can be taken to examine the existence of benefits generated through the use of CMS along with traditional instruction (e.g. student course grade, attendance, participation, satisfaction, retention), but we believe the most direct way is to examine the relationship between system usage (as measured in number of page views) and overall class grade on a 100 point scale.

At the end of the semester, the CMS usage log was analyzed and total page views were determined for each studentusage category being examined on our study. We will discuss the results of our analyses below.

\section{ANALYSIS \& RESULTS}

A multiple regression was used to examine the impact of number of page views for overall usage, as well as lecture slides and course project information on final grade. Our regression analysis (see table 1) found that the level of overall CMS usage was not statistically significant in predicting course performance. The analysis also showed that only the use of the system to view project information was statistically significant in predicting course performance.

Table 1: Multiple Regression Results

\begin{tabular}{|l|c|c|c|c|c|}
\hline \multicolumn{1}{|c|}{ Factors } & \multicolumn{2}{|c|}{$\begin{array}{c}\text { Unstandardized } \\
\text { Coefficients }\end{array}$} & $\begin{array}{c}\text { Standardized } \\
\text { Coefficients }\end{array}$ & t & Sig. \\
\hline & \multicolumn{1}{|c|}{ B } & Std. Error & Beta & & \\
\hline Page View Total & -0.04762 & 0.050801 & -0.2263 & -0.93746 & 0.351887 \\
\hline Course Project Info & 0.463714 & 0.226107 & 0.361699 & 2.050863 & 0.044194 \\
\hline Lecture Slides & 0.104419 & 0.081147 & 0.239121 & 1.286793 & 0.202595 \\
\hline
\end{tabular}

Comparing the total page views for both categories in our study reveals that students tended to use the CMS to access non-novel content much more often than novel content. Even when these totals were adjusted for grade weight (e.g. the percentage that each category accounted for in the final course grade), students were more likely to access non-novel content. 
Volume XII, No. 2, pp 95-99, 2011

Table 2: Page View Totals

\begin{tabular}{|l|r|r|rr|}
\hline & Page Views & $\begin{array}{l}\text { Percent of } \\
\text { Total Grade }\end{array}$ & $\begin{array}{l}\text { Page Views Per Percent } \\
\text { of Total Grade }\end{array}$ \\
\hline Lecture Slides & 1,860 & $75 \%$ & & 24.8 \\
\hline $\begin{array}{l}\text { Course Project } \\
\text { Information }\end{array}$ & 440 & $25 \%$ & & 17.6 \\
\hline
\end{tabular}

DISCUSSION

Our regression analysis found that the level of overall CMS usage was not statistically significant in predicting course performance (H1). However, our analysis indicated that accessing novel information (course project information) did have a significant impact on student performance (H2). Non-novel information did not appear to be significant (H3).

It is surprising that the overall number of page views was not significant in determining course performance since the earlier DOE meta analysis found that students in courses that used a blended instructional method did better than students in similar traditional courses. It could be that the blended classes in these studies included more novel content than ours did.

Although these findings may appear to support the practice of using course management systems to share novel content, we believe there is another way to interpret these results. When teaching, the ultimate goal of the instructor should be student learning as represented by student performance in the class. We believe our results suggest that some students might become dependent on the primary method of course delivery (face-to-face lecture) and neglect other information channels that the instructor may use, such as a CMS. Because of this, instructors are cautioned when using CMS to share novel information with students.

These results have important implications for universities that are implementing CMS to augment traditional faceto-face courses. If some students are not obtaining benefit from the novel information presented in the CMS, it is important to understand why. We propose a few possible reasons:

1. Because the novel content was not covered in the face-to-face meeting, students might view it as less important than non-novel content.

2. Students may be resistant to new technology.

3. Students may become myopic, focusing only on the main method of content delivery (face-to-face) and ignoring ancillary channels (CMS).

Future research will be necessary to identify what role, if any, these issues play in a student's use of a CMS. Until these questions are resolved, it may be necessary for instructors to be sensitive to these issues among their students. In addition, if feasible, universities should consider offering both traditional and blended sections of a course in which the instructor is proposing to offer novel content through a CMS.

It is important to note that number of page views is not a true measure of system usage or content usage. The number of page views does not take into account how long a student kept the content on his screen. In addition, students are free to download or print content from the course website and refer back to it as many times as necessary without reconnecting to the CMS. However, since it is not possible for us to measure student behavior that does not involve connecting to the CMS, we believe using page loads is an acceptable surrogate.

Another limitation of our study is the size of our sample. Although 76 students took part in our study, only one MIS class was examined. Our results may not be generalizable to other fields. However, we hope that the findings of our study will encourage further exploration of this topic. 
Volume XII, No. 2, pp 95-99, 2011

\section{CONCLUSION}

Our results suggest that the use of a course management system to augment a traditional face-to-face class meeting does appear to significantly improve course performance when used to share novel information. This impact is not observed when the CMS is used to share non-novel content. Unfortunately, the students in our study tended to use CMS to view non-novel information more often than novel information.

Despite this observed relationship between novel usage and student performance, we caution instructors when using a CMS to share novel content with students. Although a blended learning arrangement may work well for some students, other students may actually perform worse because of the use of the CMS to share novel content.

\section{REFERENCES}

1. Mostow, J.; Beck, J.; Cen, H.; Cuneo, A.; Gouvea, E.; and Heiner, C. (2005) “An Educational Data Mining Tool to Browse Tutor-Student Interactions: Time Will Tell!” In Educational Data Mining: Papers from the 2005 AAAI Workshop, ed. Joseph E. Beck, pages 15-22. Technical Report WS-05-02. American Association for Artificial Intelligence, Menlo Park, California

2. Piccoli, G., Ahmad, R. \& Ives, B. (2001) "Web-based virtual learning environments: A research framework and a preliminary assessment of effectiveness in basic IT skills training,” MIS Quarterly, Vol. 25, No. 4, pp. 401426.

3. Romero, C.,Ventura, S., \& García, E. (2008) "Data mining in course management systems: Moodle case study and tutorial,” Computers \& Education, Vol. 51, No. 1, pp. 368-384.

4. Russell, T. L. (1999) "The no significant difference phenomenon: A comparative research annotated bibliography on technology for distance education," Office of Instructional Telecommunications, Raleigh, NC.

5. Sarker, S., \& Nicholson, J. (2005) "Exploring the myths about online education in information systems," Informing Science Journal, Vol. 8, No. 1, pp. 55-73.

6. U.S. Department of Education (2009) "Evaluation of Evidence-Based Practices in Online Learning: A MetaAnalysis and Review of Online Learning Studies,” Office of Planning, Evaluation, and Policy Development, Washington, D.C. 